\title{
Cinsiyetlenme Üzerinden Bir Teknik Olarak Psikanalizin Histerikleştirmesi
}

\author{
Ahmet Evran \\ Orta Doğu Teknik Üniversitesi
}

\section{$\ddot{\mathbf{O} z}$}

Psikanalizin tekniği analizanın histerikleştirilmesi üzerinden incelenebilir. Yabancılaşma ve ayrışma süreçlerini bir bütün olarak ele alan Lacan'ın cinsiyetlenme hipotezi, arzunun nasıl başladığına, fallus ve jouissance ilişkisine ve arzuyla beraber gelen nesne $a$ kavramına toptan bir bakış sağlayarak klinik yapılar arasında nasıl bir ayrımın yapıldığının anlaşılmasına yardımcı olur. Klinik yapılar ile cinsiyetlenmenin ilişkisi de analizin neden histerikleştirdiğini anlamamıza yardımcı olabilir. Histerik ve kadın ile obsesif ve erkek arasında kurulan paralelliklerin altını doldurmada Lacanyen psikanalizin kendi içinden çıkan cinsiyetlenme kavramına değinmek bir gerekliliktir. Bu yazıda, temel üç klinik yapı olan psikoz, nevroz ve perversiyonun farklı bakış açılarına göre nasıl açıklanabileceğinden destek alınarak dişil ve eril jouissance'ın analizin tekniğiyle bağlantısı incelenmiştir. Dişillik ve erillik diyalektiğinde oluşan öznenin, analizde Ötekinin arzusuyla yüz yüze gelmesi kendini ancak dişil bir pozisyonda bırakarak histerikleştirmesiyle mümkün olabilir. Bu da bilinçdışının çalışılmasına imkân veren temeli oluşturur.

Anahtar Sözcükler: Psikanaliz, cinsiyetlenme, klinik yapılar, fallik jouissance, dişil, eril 


\title{
Psychoanalysis Hystericizes as a Technique: An Explanation upon Sexuation
}

\author{
Ahmet Evran \\ Middle East Technical University
}

\begin{abstract}
Fundamental technique of psychoanalysis can be studied on the fact that it hystericizes. Lacan's hypothesis on sexuation in which alienation and separation are held together, reflects on the origins of desire, the relation between jouissance and phallus, and object $a$ in association to desire. This makes it possible to look upon the clinical structures from a different perspective. In turn, the relation between sexuation and clinical structures of psychoanalysis can help us understand why psychoanalysis hystericizes. It is a necessity to analyze sexuation to fill the gaps in the assumed overlaps between woman/hysteric and man/obsessive. In this paper, how phallic and feminine (Other) jouissance relate to psychoanalytic technique is studied based on the different interpretations of three basic clinical structures, which are psychosis, perversion and neurosis. It is only possible when the analysand is in the position of the hysteric or when s/he is hystericized, that the subject as a product of feminine and masculine dialectic can encounter with the enigmatic desire of the Other. This is the condition for working through the unconscious in psychoanalysis.
\end{abstract}

Keywords: Psychoanalysis, sexuation, clinical structures, phallic jouissance, feminine, masculine 


\section{Cinsiyetlenme Üzerinden Bir Teknik Olarak Psikanalizin Histerikleştirmesi}

Psikanalizin en temel tekniği bilinçdışını çalışarak kişiyi önce arzunun öznesine, oradan da dürtünün öznesine götürmektir (Fink, 1997, s. 209). Özne, konuşma eylemi - daha doğrusu konuşma hareketi - sırasında ortaya çıkan, bir göstereni başka bir gösteren için tutan ve sonra bilinçdışına giden, bu nedenle üstü çizgili olandır. En basit şekliyle, konuşan, yazan, okuyan, düşünen özne gösterenden gösterene atlayarak jouissance elde etmeye, onu çoğaltmaya ve sürdürmeye çalışır (\$ $\diamond$ a) ${ }^{1}$. Jouissance en temel anlamıla kaotik bir kaynaşma ve canlılık durumudur ve bu haliyle fallusa gönderme yapar. Fallusu bir nevi bir ötekiyle bir $(1)^{2}$ olma hali olarak ele alırsak, jouissance kaygının eşlik ettiği haz ve acının aynı andalığı şeklinde algılanan; bu haliyle haz ilkesinin ötesinde olan ve bu birlik haline gönderme yapan şeydir. Örneğin, jouissance, arzu nesnesine (a) atıfta bulunarak bir şeyin imgesi ve kelime(si) arasındaki açıklıkta ortaya çıkar (Ragland, 2004, s. 9). Arzu nesnesine atıfta bulunmasını ve Sembolikle ilişkisini Lacan'ın cinsiyetlenme (sexuation) tezine bakarak açıklayabiliriz ${ }^{3}$.

Cinsiyetlenme insanın metaforik açıdan ilk olumsuzlaması olarak görülebilir (bu olumsuzlama kendi içinde üç farklı olumsuzlama şeklinde ortaya çıkar) (Lacan, 2002a); insan hayvanı cinsiyetlenmeyle bir hayvan olmanın dışına yerleşir. Bebek, yaşamı için ihtiyaçlarını karşılamasını şart koşan dürtülerle hareket eder. Bir Şey ${ }^{4}$ ve o şeyin imajının ayrılmadığı bir durumdayken ötekinin varlığıyla karşılaşır. Ancak ötekinin varlığı devamlılık arz etmez. Annenin bakış alanından kaybolup tekrar belirmelerinde, memeden akan sütün kaybolup tekrar geri dönmesinde, sessizlikte seslerin durup tekrar başlamasında, boşluklar Ötekinin devamlılığını ve tutarlılı̆̆ını bozar. Bu şekilde Ötekinde merkezi bir boşluk oluşur ki Lacan bu boşluğa nesne a der. Ötekinin arzusunu harekete geçiren $a$ içselleştirilerek öznenin $a$ 'sına dönüşür.

Freud'un içgüdü ve biyolojiyle açıklamaya çalıştığı psişik gerçeklik ve fiziksel gerçeklik

${ }^{1}(\$ \diamond a)$ nın okunuşu üstü çizgili özne nesne a yani arzu nesnesine gidişinde bir devinim olarak ortaya çıkar. Mantıksal olarak sadece gösterenler arasında, bedende tanınamaz olarak vb. ortaya çıkışları nedeniyle üstü çizgilidir; diğer bir deyişle bilinçdışıdır.

${ }^{2}$ Buradaki 1 matematiksel bir gösterim olarak algılanmalıdır. Özne 0 yani ‘yok' ile 1 yani ‘var' arasında salınır ve nesne a ya gidip dönüşleriyle bu arada yer alır. Fallusa sahip olmak hipotetiktir ve kronolojik bir olgu olarak anlaşılamaz. Erkek fallusa sahipmiş gibi, kadın sahip olacakmış gibi yaşar ve ikisi de fallus tarafından tanımlansa da aslında 1'lik durumuna erişemez.

${ }^{3}$ Sexuation kelimesi cinsiyetlenme ya da cinsiyetleşme olarak çevrilebilir. Cinsiyetlenme kavramının seçimi ile günümüz toplumsal cinsiyet teorilerinin dilinden ziyade psikanalitik bir bağlamda kişinin cinsel olarak kuruluşu kastedilmektedir. Cinsiyetlenme, arzu ve jouissance diyalektiğini yürütmeyi sağlayan ve özneyi dişil ve eril şekillerde kuran "cinsel" ile bağlantılıdır.

${ }^{4}$ Bir şeyin göstereni, anlamı(gösterileni) ve asıl Şey arasındaki farka vurgu yapmaktadır. 
farkını, Lacan parçalanmış dürtülerle açıklayarak Freud'un sözde indirgemeciliğini aşmıştır ${ }^{5}$. Bebeğin ötekindeki tutarsızlık ve devamsızlığa sebep olan boşlukları (boşluğu) fallik gösterenle özdeşleşerek doldurmaya çalışması temel dört dürtünün (skopik, vokal, anal ve oral dürtüler ${ }^{6}$ ) parçalanmasına yol açar (ve zaten asla tam olamamışlardır) (Dravers, 2011). Fallik gösterenle özdeşleşme öznenin Ötekinin arzusunu anlama gerekliliğinden gelir ve dolaylı olarak da anlamın genel bir etki olarak oluşabilmesinin şartıdır (Lacan, 2002b). Çocuk imge ve şey’i birbirinden ayırma ve şey’i gösterenle belirtme talihsizliğine düşer. Bu talihsizliktir çünkü şey ve imgesi ayrıldığında jouissance (Öteki Jouissance) ${ }^{7}$ kaybolur. Nesne a'nın ilk ayağı bu kayıptır. İkinci ayak, şey ile göstereni arasındaki kayba işaret eder ve imgesel bir kayıp olarak karşımıza fallus çıkar. Fallik fonksiyon olarak bu kayıp kastrasyona gönderme yapar. Fallusun kendisinin bir göstereni olmasa bile bilinçdışında gösterileni yani Gerçekte bir anlamı vardır. Birçok gösterinin olması ve bir gösterenin başka bir gösterene götürmesi, gösterenlerin birbiriyle bağlantılı olarak ancak ve ancak gösterenler zinciri içinde anlam üretebilmesi de üçüncü ayağı oluşturur. Üç mantıksal zamanda oluşan tüm bu kayıpların merkezine de nesne a merkezi bir eksiklik olarak oluşur. Yukarıda bahsedilen mantıksal zamanda gerçekleşen, üç alt olumsuzlamadan oluşan ve $a$ 'yı ve özneyi ( $\$ \diamond a$ ) yaratan süreci böyle özetleyebiliriz.

Dürtüler parçalandıktan sonra nesne a'nın içerikleri olarak kayıp nesnelere yönelirler. Örneğin Bakış (Gaze) - Möbius Şeridi ile tarif edilebilir - bakanın ve Ötekinin bakışının aynı düzlemde ve aynı şeyler olması arzunun Ötekinin arzusu olmasıyla paraleldir. Arzunun oluşması da nesne a'nın oluşması ile eştir. Özne, $a$ 'ya çok yaklaştığında arzu yerini jouissance'a bırakır ve kaygı bir koruyucu olarak arzu ile jouissance arasında ortaya çıkar (Salecl, 2013, s.57). Diğger bir deyişle, eksikliğin (a) eksilmesi yani $a$ 'nın bir fonksiyon olarak düşmesi özne tarafından tehdit olarak algılanır ve bu algı kaygı oluşturur. Kayg1, eksikliğin eksilmesi kadar eksikliğin yerine bir nesne geldiğinde de - mesela

${ }^{5}$ Freud'un önündeki engellerden en önemlisi, İçgüdü (Instinct) gibi vücutsal bir kavram üzerinden psişik gerçek (interior reality) ve fiziksel gerçek (sense data) arasında ayrım yapmaya çalışmış olmasıdır. Lacan bu noktada güdüyü yerleştirir ve yabancılaşma aşamasıyla dilin önemine vurgu yapar.

${ }^{6}$ Dört temel dürtü nesne a'nın farklı formlarına giden ve bilinçdışının nabzını oluşturan bileşenler olarak adlandırılabilir. Oral dürtünün nesnesi meme, anal dürtünün nesnesi dışk1, skopik dürtünün nesnesi bakış ve vokal dürtünün nesnesi sestir. Dürtüler kastrasyonla beraber parçalanır ve sağladıkları jouissance bedene ve dile yerleşir. Böylece her birey tikellikleri içerisinde kendi tarihlerine ve semptomlarına sahip olurlar çünkü her özne kendi karşılaşmalarını ve olaylarını yaşar ve bu jouissance'ın konumlanışını kişiye özgü hale getirir (Dravers, 2011). Dürtüler aslında hiç tam olmamışlardır çünkü Ötekinin söylemi içine doğmak bunu şart koşar. Ancak dürtüler nesneleriyle olan ilişkileri içerisinde bütünlüklü kalabilirler ki bu dört nesne-meme, dışkı, bakış, ses- nesne a'nın değişik formalarıysalar bilinçdışının nabzı olan dürtülerle özne arası sanıldığı kadar opak değildir.

${ }^{7}$ Öteki Jouissance kadınların erişim alanında olan, erişmek zorunda kalmadıkları, anneyle güdüsel düzeyde bir özdeşleşme anına atıfta bulunan jouissance’tır. Bebeğin yabancılaşma öncesinde kaybettiği zevk olarak anlaşılabilir. Aynı zamanda fallik jouissance'tan daha öte ve annelik durumuyla alakalı olduğu unutulmamalıdır. Daha fazla bilgi için Alves ve Poli'nin makalesine bakınız. 
aşk durumunda - oluşabilir ve arzunun jouissance'a yol/yer vermesini haber veren mekanizma olarak kaygı çıkar. Annenin arzusundan ayrılamama durumunu da -yani babalık fonksiyonu başarısız olduğunda- eksikliğin yerinde annenin olmasıyla psikotiklerin neden bu kadar kaygılı oldukları arasında bir bağlantı kurulabilir mi?

Peki, bunların cinsiyetlenmeyle ilgisi nedir?

Cinsiyetlenmenin anlamı öznenin kendini hayvanlar dünyasından insanlar dünyasına yani sosyal olan yere konumlandırmasıdır. Diğer bir deyişle, cinsiyetlenme gösterenler zinciri de dediğimiz insandaki dille şekillenen zihnin mekanizmasının kurulmasının şartıdır. İnsan zihninin diyalektik olarak kurulmasının (etkin/edilgen, artı/eksi, kadın/erkek, eril/dişil) kökenleri Lacanyen psikanalize göre öznenin cinsiyetlenmesiyle yani cinsiyet ayrımının fark edilmesiyle bağlantılıdır (Ragland, 2004, s. 22). Jouissance'ın tözleri olan eril (masculine) ve dişil (feminine), öznenin yapılanmasını sağlar. En basit şekliyle, erkek çocuk anneden tam olarak ayrılarak babanın hayırı'na (sembolik yasaya) boyun eğer. Ancak erkek çocuğun boyun eğmesi kendini babanın yasasına bir istisna tutarak, yani bir soyutlama yaparak mümkün olabilir. Diğer bir deyişle, erkek çocuğun babayla özdeşleşmesi zaten babanın kendini bir istisna tutarak kuralı dayatması mantığını erkek çocuğun da içselleştirmesiyle mümkün olabilir. Benzer bir düşünce ancak sonsuzluğun kavranmasıyla bir şeyin sonluluğunun anlaşılması olabilir. Baba, Freud'un Totem ve Tabu'da kullandığı babalarını öldüren kardeşler mitindeki baba gibi kendi yasasına bir istisna olmalıdır çünkü yasayı meşrulaştıran şey kendinin bir istisna olmasıdır. Diğer taraftan, kız çocuk babanın hayırı 'na boyun eğerken aynı zamanda anne ile de özdeşleşir. Özdeşleşmenin tek bir ötekiyle olmaması kız çocuğa Gerçek (reel) ile bir bağlantı sağlar ki bu bağlantı dürtünün gerçeğiyle bir bağlantı ihtimalidir; çünkü özne tamamen yasanın altında olmama serbestliği kazanır. Bunun anlamı erkeklerin daha çok efendi söylemine benzer bir mantıkla Sembolik'in içinde kapalı olmaları ve doğrudan daha fazla süperego etkisi altında olmalarıyken, kadınların süperego diktasına karşı daha esnek olabilmeleridir (Ragland, 2004, s. 16). Lacan, kadınların Gerçek ile bağlantılarından gelen bir ilave (Other - Öteki) Jouissance'a da erişimleri olduğunu öne sürmüştür (Alves ve Poli, 2016). Gerçeğe daha yakın bir yerde konumlanmalarından fallusa sahip olmama durumunda diretebilirler ve Gerçek Kadın'a ${ }^{8}$ (The Woman) yani Öteki

${ }^{8}$ The Woman/Kadın kavramı bir öz (essence) olarak Kadın'ın var olmamasına gönderme yapar. Erkek ya da ataerkil Sembolik, Kadın’ın özünü yok sayarak Erkek'in özü olduğunu ima eder. Bu sebeple insanın ilk olumsuzlaması olarak okuyabileceğimiz cinsiyetlenmenin gücünü aldığı yerdir ve doğrudan Gerçek, Bilinçdışı gibi kavramların bulunduğu dişil tarafta yer alır. Ragland'tan alıntılamak gerekirse (2004):

"...Man is man only insofar as he retains a false belief regarding Woman, a belief that surprisingly belongs to the feminine side of sexuation where the real, unconscious, and contingent prevail. This contradiction leads Lacan to the "feminist" proposition that the masculinist illusion of wholeness is based on a fantasy essentialization of the woman (who exists), such that some myth of the whole, essential, primordial mother continues to serve the male, unconsciously, as a guarantee to a stable, logical dependable universe.” (s. 24) 
Jouissance'a ulaşmaya çalişabilirler (Miller, 2000).

Özne ve $a^{\prime}$ nın ortaya çıkması ve bunların bilinçdışı dürtüler ve dürtülerin nesneleriyle ilişkiselliği, bir üstte anlatılan iki farklı anatomik cinsiyetin nasıl farklı stratejilerle kastrasyonunu yaşadığı aslında çocuğun yabancılaşma sürecinde fallik gösterenle özdeşleşmesine bağlıdır. Burada dikkatli olunması gereken yer, yasanın sadece dille bağlantılı ve gelişimsel bir yapıtaşı olduğu düşüncesinin yanlış olmasıdır. Yasa (Law) daha çok fark/ayrılık yasasıdır (Law of Difference) ve dışarıdan geldiği için sembolikten ayrı olduğu düşünülemez; ancak öznenin kendini babanın hayırı'nın yerini tutan bir şeyle özdeşleştirmesi (Tanrı, gerçek baba, lezbiyen bir partner, öcüler) aynı zamanda başka bir şeyle özdeşleşmemesiyle mümkün olabilir (Grigg, 1993). Benzer bir şekilde jouissance' in dişil ve eril tözlerini de bu farkı jouissance boyutunda yansıtıyor olduğunu söyleyebiliriz. Fallik gösteren $\left(\mathrm{S}_{1}\right)$ özneyi diyalektik olarak dişil ve eril şekillerde kurar (Grigg, 1993). Özne biyolojik ve sembolik cinsiyeti fark etmeksizin Ötekinin arzusu karşısında dişildir ancak Ötekinin arzusuna yanıt verirken erildir denilebilir.

Fallik gösterenin gösterileni de Gerçek’te yani travmatik ve cinsel olanın bulunduğu alanda, öznenin erişimi dışındadır. Bunun kanıtı şöyle olabilir: iki a harfinin iki farklı kelime içinde veya iki ayrı zamanda fonetik ve oluşturdukları anlam bakımlarından farklı olması $(a \neq a)$, iki fonemin birbirine asla eşit olamaması durumu dilin insan zihnine önceden yerleştirilmemiş olduğunu gösteriyor olabilir. İnsan zihni dediğimiz şey daha çok gösterenler zincir(ler)i şeklinde anlaşılabiliyorsa $\left(\mathrm{S}_{1} \rightarrow \mathrm{S}_{2}\right)$, hafizanın ve anıların zihne girmeleri ancak babalık fonksiyonun etkisine bağlı olarak gerçekleşebilir ve dil kullanımında ustalaşmadan hafızanın açıklanabilirliği yoktur çünkü hafıza mefhumu daha oluşmamıştır. Gerçek'i, bilinçdışında olan ve erişemediğimiz anlamların olduğu (ya da anlamın kaybolduğu) yer olarak alırsak, Sembolik yasada olma koşulunun zaten bunlara erişememe üzerine kurulduğunu anlayabiliriz. Bilinçdışı materyal ve anlam, semptom halinde ve belki de $a$ biçiminde üç halkayı (Sembolik, İmgesel, Reel) bir arada tutan dügümdür. Düğüm sürekli gösteren değiştirir, babalı fonksiyonun yerini sürekli yeni bir kayıp alabilir ya da ölüm gibi daha trajik bir kayıp babalık metaforu yerine işlev görmeye başlayabilir.

İnsan zihninin kurulması, özneye eril ve dişil tözler olmak üzere jouissance’1 elde etme, üretme ve sürdürme imkânın tanınması ve nesne a'nın bir eksiklik olarak, özneyi de bu eksiklikte bir varlık olarak konumlandırma durumu cinsiyetlenmeyle bu şekilde bağlantılıdır. Kadının (ve dişil jouissance'ın) genel geçer olarak histerikle bağdaştırıldığı varsayımıyla hareket etmemek için, nevrozlarda obsesif ve histerik yapıların oluşumuna göz atmak gerekir.

Klinik yapıları sınıflandırma birkaç farklı şekilde yapılabilir. Fink'e (1997) göre babanın hayırı'na göre alınan pozisyon kişinin yapısını belirler. Psikotik yapıda babanın adının toptan sükûtu varken, pervert özne babanın hayırı'nı kabul eder ancak annenin zevk nesnesi olma konumundan 
ayrışması gerçekleşmediği için ancak Ötekinin $a$ 'sı olarak var olabilir (being) yani ayrışmayı tanımaz. Nevrotik özne ise yabancılaşma ve ayrışma anlarını yaşar ve bastırmayla (ve bastırılanın geri dönmesiyle) kendini özne olarak kurar. Nevrozlarda altyapılar olarak yer alan obsesyon ve histeri, öznenin annenin arzusunun enigmatik olması karşısında Ötekine (mOther) göre aldığı konumla belirlenir. Arzunun enigmatik olması arzunun asıl nesnesinin belirsizliğinden ve bu nesnenin ulaşılamaz olmasından gelir, arzu hep arzulamak için bir arzudur. Bir tarafta obsesif özne kendi arzu nesnesinin Öteki (anne) ile bağlantılı olduğunu bastırırken ve kendini tam özne olarak görürken (S $\diamond$ $a)^{9}$; histerik özne kendini Ötekinin arzusunun nesnesi $(a)$ konumuna yerleştirir $(a \diamond \mathbb{A})^{10}$ ve Ötekinin arzusunu tatmin etmemeye dayalı bir strateji izler. Obsesifin kendini tam özne olarak görmesi bilinçdışından uzaklaşmasının bir göstergesidir. Nesne a'nın Ötekinin arzusuyla bir bağlantısının olduğunun bastırılması bilinçdışı olan Ötekine ve nesne $a$ 'ya mesafe koymak demektir. Bu kişiyi bilinç durumunda bir zihinsel mastürbasyona hapseder. Histerik ise kaybın nesnesinin (a) yerine geçerek Ötekinin arzusunu tatmin etmeme üzerinden kendi bilinçdışı arzusunu tatmin eder. Bu anlamda histerik bilinçdışına daha yakın bir pozisyondadır. Bu bakış açısına göre obsesyon bir erkek pozisyonu gibi yansırken, histerik de tam bir kadın pozisyonu gibi algılanıyor olabilir çünkü sosyolojik veya biyolojik indirgemeyle aktif/pasif ya da arzulayan/arzulanan ikilileri bu modele çok kolay oturur. Bu nedenle istatistiksel olarak bir veriye dayanmadan erkeklerin çoğunun obsesif, kadınların çoğunun da histerik olduğu inancı hakimdir (Fink, 1997, s. 134).

Temel üç klinik yapının bulunduğu görüşüne karşın bir diğer bakış açısına göre temel üç yapının dışında normatif dişil bir yapının da bulunduğu hipotezi daha dolu bir bakış sağlayabilir. Buna göre ayrışma mantıksal zamanında değil cinsiyetlenme sürecinde fallusa yani nesne a yı bir eksiklik olarak oluşturan fonksiyonlara karşı takınılan tavır ve zihnin bir tür alışkanlığı gibi görülebilir. Örneğin psikotik fallusu sükût eder, ona göre iki tip jouissance'ın yani dişil ve eril jouissance'ın olması imkânsızdır ve diyalektik düşünce oluşmaz. Pervert fallusun aidiyetini yok sayar, ona göre fallus herkeste ve her şeyde imkânlıdır. Nevrozlarda cinsiyetlenme tamamen sağlandığı için fallus birinde olmak zorundadır ancak kimde olduğunun bir önemi yoktur çünkü fallusa sahip bir özne ve sahip olmayan bir özne yeterlidir. Maskeli özne (Masquerade) ${ }^{11}$ ise saklandığı kadınlık/erkeklik

\footnotetext{
${ }^{9}$ Obsesif, kendini fallusa sahip varsayarak, üzeri çizgili olmayan özneymiş gibi, tam olduğunu düşünerek arzu nesnesine gider.

${ }^{10}$ Histerik, bilinçdışı büyük Öteki’ne doğru, onun arzu nesnesi konumunda yaklaşır, şeklinde okunabilir. Üzeri çizgili büyük A burada Fransızca Autre (Öteki) sözcüğünün baş harfinden gelir.

${ }^{11}$ Masquerade, önce Joan Riviere daha sonra feminist teorisyenlerce ortaya atılmış, post yapısalcı toplumda daha çok kadınların olsa erkeklerin de sembolik cinsiyetlerinin arkasına saklanarak Sembolik'ten kaçışlarını ifade eder. Bir kadının kadınlığını kullanarak eril bir Sembolik’te hayatta kalmaya çalışması durumunun yapısıdır. Feminen bir erkeğin oluşturduğu ilk rahatsızlık durumu, evrensel bir Kadın'a gönderme yaparak, eril yapıdaki Sembolik'e bir öz olarak Kadın'ın varlığını hatırlattığındadır. Fallusu (eril olarak Kadın'ın yokluğu üzerinden) referans alarak şekillenen ve
} 
maskesi ardından fallusa nesne a üzerinden sahip olmaya çalışır (Riviere, 2015).

Birinci bakış açısına göre erkekler ve kadınların obsesif ile histerik pozisyonlara denk gelmesi tezi tam meşrulaştırılamaz. İkinci bakış açısına göre ise eğer böyle bir sınıflandırma yapılabilirse cinsiyetlenmeye atıfta bulunulması şarttır. Cinsiyetlenmeye göre kadınların babanın hayırı'na uyarken aynı zamanda anne ile özdeşleşmelerinin verdiği tam olarak Sembolik’in söylemi içerisinde yer almama durumu, kadınların Gerçek (bedensel ve anlamsal) olanı imgesel bir şekilde yaşayabilmesine izin verir. Erkeklerde ise imgesel olan (fallus $-\phi$ - negatif imgesel fallus kayıp edilen ama aslında kaybedilmeden önce olmayan jouissance’tır) sembolik olarak yaşanır. Erkekte Sembolik o kadar güçlüdür ki semboliğindeki Erkek'in (eril olma durumunun) içini dolduramazsa bir travmayla karş1 karşıya kalabilir (Salecl, 2013, s. 85). Belki de maskeli erkek, travmayı duygulanımla (mutluluk, üzüntü, vs.) doldurabiliyorken, obsesif daha fazla kural üretip travmatik olandan kaçınmaya çalışabilir ve travmatik olanla yüz yüze geldiğinde çaresizlik içinde tehlikeyi işaret eden kaygıyı deneyimleyebilir ve bu öfke olarak çıkabilir. Bu bilgiler ışı̆̆ında obsesif $a$ 'ya ve Ötekine göre, bilinçdışından uzaklaşarak (anne ile) bir kaynaşma ve bütünleşme durumuna atıfta bulunan (imgesel) fallusun kaybını sembolik olarak telafi etmeye çalışan bir özneye denk düşmesidir. Histerik ise bilinçdışına daha yakın konumlanışıyla travmatik, bilinemez anlamı ve bu anlamın bedende ortaya çıkışını imgeselleştirerek yaşar ve bu, kadınlarda dişil jouissance'ın yanında bir Öteki jouissance'a erişimleri olduğuna işaret eder. Bu anlamda bir erkek/obsesif ve kadın/histerik benzeşmesi meşrulaştırılabilir.

Psikotikler hariç herkeste dişil ve eril jouissance'ın var olduğu gerçeğine bağlı olarak psikanalizin uğraşı, özneyi daha çok dişil jouissance tarafına çekmektir çünkü cinsiyetlenme anında oluşan özne her iki jouissance'a erişimi olsa da Sembolik alanda (bu durumda ataerkil/eril bir alan) yaşamak zorunda olduğundan baskın jouissance eril olandan gelir. Gösterenlerle yazılan bedene ya da travmatik olan ve gösterenler zinciri içinde noktalamalarla kurulan semptoma ulaşmak Gerçek’e yakın olmayı gerektirir. Bu sebeple nevrotik analizanın altyapısı fark etmeksizin histerik tarafa çekilmesi, histerikleştirilmesi/dişilleştirilmesi şarttır. Böylece özne bilinçdışından daha fazla materyal getirme ve bunlar üzerinde çalışma imkânına sahip olur. Noktalamalar, değişken süreli seanslar, aktarıma izin verme, yorumlamaların arzunun enigmatik durumunu yansıtması için kişiyi daha fazla konuşmaya itecek türden olması gibi yöntemlerle analizan histerikleştirilir. Histerinin temelinde yer alan üstü çizili Ötekinin yani bilinçdışı olan Ötekinin $a$ 'sı şeklinde konumlanma, skopik dürtü alanında (Bakış) analistin Ötekinin yerini doldurması ve Ötekinin enigmatik arzusunu temsilen bulunması kişiyi zaten histerik pozisyona sokmayla ilgilidir. Histeriğin söyleminde olduğu gibi özne, $a$ konumundan yola

gerçekleşen cinsiyetlenmenin ve Sembolik’e girişin maskeli bir yapı da oluşturabileceği savını es geçmemek gerekir. 
çıkar ve Ötekindeki Özne olarak $S_{1}$ üzerine katlanmış ve semptomu bir fantezi olarak kurgulamış olan gösterenlere ulaşarak tarih dışı bilgisini yeniden üretir (Schwartz, 2015). Psikanalizin en temel tekniği budur.

Analizin sonu da nevrotik öznenin Öteki için kim ve ne olduğunu sorularını bir kenara bıraktı̆̆ (ve belki de) arzusunun (ne istediğini) ve kısmi dürtülerinin farkında olarak yaşamaya başladığı yerdir. 


\section{Kaynakça}

Alves, M. B., ve Poli, M. C. (2016). When a woman is mother: Feminine jouissance in motherhood. Ágora: Estudos em Teoria Psicanalitica, 19(2), 191-

207. https://dx.doi.org/10.1590/S1516-14982016002003

Dravers, P. (2011). The drive as a fundamental concept of psychoanalysis. Retrieved from: http://londonsociety-nls.org.uk/Publications/023/Dravers-Philip_The-drive-as-afundamental-concept-of-psychoanalysis.pdf

Fink, B. (1997). A clinical introduction to Lacanian psychoanalysis: theory and technique.

Cambridge, Mass.; London: Harvard University Press.

Freud, S. (2003). Totem ve tabu. (Çev. Kamuran Ş.) İstanbul: Say Yayınları

Grigg, R. (1993). Lacan's four discourses. Analysis, 4, 33-40.

Lacan, J. (2002a). The function and field of speech and language in psychoanalysis. In B. Fink

(Trans.), Ecrits: the First Complete Edition in English (pp. 197-268). New York, NY: W.

W. Norton and Company.

Lacan, J. (2002b). The signification of the phallus. In B. Fink (Trans.), Ecrits: the First

Complete Edition in English (pp. 576-584). New York, NY: W. W. Norton and Company.

Miller, J. (2000). On semblances in the relation between the sexes. In Renata S. (Ed.) Sexuation:

SIC 3. (pp. 13-27). Durham and London: Duke University Press

Ragland, E. (2004). The Logic of Sexuation: From Aristotle to Lacan. Albany: State University of New York Press.

Riviere, J. (2015). Womanliness as a masquerade. In R. Grigg, D. Hecq, C. Smith, R. Grigg, D. Hecq, C. Smith (Eds.), Female sexuality: The early psychoanalytic controversies (pp. 172-182). London, England: Karnac Books.

Salecl, R. (2013). Kaygı üzerine. (1. Basım). İstanbul: Metis.

Schwartz, S. (2015). The nodal point that is desire. Analysis, 20, 147-152. 